\title{
Fuzzy containers allocation problem in maritime terminal
}

\author{
Seyed-Mohammad Seyed-Hosseini; K. Khalili Damghani \\ Department of Industrial Engineering, Faculty of Engineering, Science \& Research Branch, Islamic Azad \\ University, Tebran (IRAN) \\ seyedhoseini@yahoo.com; kaveh.khalili@gmail.com
}

Received February 2009

Accepted July 2009

\begin{abstract}
Containers allocation in terminals has attracted lots of research works due to practical \& theoretical importance in transportation literature. In this paper, we developed a fuzzy mathematical programming model for solving problem of allocating the containers in terminal area. The objective is minimizing the total distance traversed by the containers from the ship to the terminal area they are assigned. Fuzzy set concepts are used to treat imprecision regarding the distances between berth and terminals area, number of containers in an arrived ship and estimation of available area in each terminal at a port. We proposed two types of models for optimistic and pessimistic situations. The proposed models have been coded in LINGO8.0 solver and a numerical example has been solved for illustration purpose. The full analysis of the proposed models can cause an optimum allocation of containers of several ships to different terminals of berths in fuzzy environment.
\end{abstract}

Keywords: fuzzy programming, fuzzy berth allocation, fuzzy container allocation

\section{Introduction}

Nowadays maritime transportation has an essential role in economies as it permits goods exchange between far-off countries. Application of containers is a proper technology for transporting freight, especially on long maritime routes. There are a large number of ports around the world, ranging from single berth locations 
handling a few tons a year to multipurpose one which handle up to several million tons a year. Over the last decades the use of containers for general cargo has extended extremely. Containers are large metal modules made in universal standard dimensions and measured in multiples of twenty feet called "twenty foot equivalent units" (TEUs). Containers require less product packaging. They help reducing defect, and they result in higher productivity during the handling process. Moreover containers allow for inter-modal transportation because transshipment between ships, trucks or trains is easily performed (Caramia \& Dell'Olmo, 2008).

Containers allocation in terminals has attracted lots of research works due to practical \& theoretical importance in transportation literature. Several extensions of the problem have been considered in this area. The variety of research work about container allocation, berth allocation problem (BAP) or any related topic is impressive. Researchers have tried to map their assumptions about the problem and have developed a suitable procedure like mathematical programming, heuristic/ meta-heuristic and etc. The emerged problems in this family have either theoretical or practical offspring and are mainly categorized in NP-Hard class. Some of the last research works in this area can be outlined as: Hansen et al. (2008), Liang et al. (2008), Imai et al. (2008), Canonaco et al. (2008), Imai et al. (2008), Imai et al. (2007), Cordeau et al. (2007), Wang and Lim, (2007), Li et al. (2007).

To our best knowledge, there are few research works in fuzzy BAP, although real world problems are faced with ambiguous parameters which could efficiently be modeled through fuzzy concepts. In this paper, we define and attack Containers Allocation Problem in Maritime Terminals in fuzzy environment. The distances between berth and terminal area, number of containers in an arrived ship and estimation of available area in all terminals of port are assumed to be positive Trapezoidal Fuzzy Numbers (TrFNs) which will be define in section 2. The objective is minimizing total traversed distance by the containers from the ship to the terminals area they are assigned in an ambiguous environment. The following sections of this paper are arranged as below. Some well-known and main arithmetic operator in fuzzy environment which is used in this paper and their associated notations are introduced in section 2 . Section 3 is allocated to define the problem scope and assumptions. Crisp model and proposed fuzzy model are also represented in section 3. Experimental results are outlined in section 4. Finally in the $5^{\text {th }}$ section the paper will be ended with a brief summery and conclusion. 


\section{Fuzzy Definitions}

Let $\mathrm{X}$ be the universe of discourse, $X=\left\{x_{1}, x_{2}, \ldots, x_{n}\right\}$. A fuzzy set $\tilde{A}$ of $\mathrm{X}$ is a set of order pairs $\left\{\left(x_{1}, \mu_{\tilde{A}}\left(x_{1}\right),\left(x_{2}, \mu_{\tilde{A}}\left(x_{2}\right), \ldots,\left(x_{n}, \mu_{\tilde{A}}\left(x_{n}\right)\right\} \quad\right.\right.\right.$ where $\mu_{\tilde{A}}: X \rightarrow[0,1]$ is the membership function of $\tilde{A}$, and $\mu_{\tilde{A}}\left(x_{i}\right)$ stands for the membership degree of $x_{i}$ in $\tilde{A}$. Some definitions are presented as follow:

Definition2.1. When $X$ is continuous rather than a countable or finite set, the fuzzy set $\tilde{A}$ is denoted as: $\tilde{A}=\int_{X} f_{\tilde{A}}(x) /(x)$, where $x \in X$.

Definition2.2. When $X$ is a countable or finite set, the fuzzy set $\tilde{A}$ is represented as: $\tilde{A}=\sum_{i} f_{\tilde{A}}\left(x_{i}\right) /\left(x_{i}\right)$ where $x \in X$.

Definition2.3. A fuzzy set $\tilde{A}$ of the universe of discourse $\mathrm{X}$ is normal when its membership function $\mu_{\tilde{A}}(x)$ satisfies: $\max _{x} \mu_{\tilde{A}}(x)=1$.

Definition2.4. A fuzzy set $\tilde{A}$ in $\mathrm{X}$ is convex if and only if for every pair of point $\mathrm{x} 1$ and $\mathrm{x} 2$ in $\mathrm{X}$, the membership function of $\tilde{A}$ satisfies the inequality

o $\quad \mu_{\tilde{A}}\left(\beta \cdot x^{1}+(1-\beta) \cdot x^{2}\right) \geq \min \left(\mu_{\tilde{A}}\left(x^{1}\right), \mu_{\tilde{A}}\left(x^{2}\right)\right)$, where $\beta \in[0,1]$.

Definition2.5. A fuzzy number is a fuzzy subset in the universe of discourse $X$ that is not only convex but also normal.

Definition2.6. The $\alpha$-cut $\tilde{A}_{\alpha}$ and strong $\alpha$-cut $\tilde{A}_{\alpha+}$ of the fuzzy set $\tilde{A}$ in the universe of discourse $X$ is defined by

o $\quad \tilde{A}_{\alpha}=\left\{x_{i}: \mu_{\tilde{A}}\left(x_{i}\right) \geq \alpha, x_{i} \in X\right\}$, where $\alpha \in[0,1]$

o $\quad \tilde{A}_{\alpha+}=\left\{x_{i}: \mu_{\tilde{A}}\left(x_{i}\right)>\alpha, x_{i} \in X\right\}$, where $\alpha \in[0,1]$

Definition2.7. A fuzzy set $\tilde{A}$ of the universe of discourse $\mathrm{X}$ is convex if and only if every $\tilde{A}_{\alpha}$ is convex, that is $\tilde{A}_{\alpha}$ is a close interval of $\mathfrak{R}$. It can be written as: 
o $\quad \tilde{A}_{\alpha}=\left[p_{1}^{(\alpha)}, p_{2}^{(\alpha)}\right]$, where $\alpha \in[0,1]$.

Definition2.8. A trapezoidal fuzzy number can be defined as a $\tilde{m}=(a, b, c, d)$, where the membership function $\mu_{\tilde{m}}$ of $\tilde{m}$ is given by

$$
\mu_{\tilde{m}}(x)=\left\{\begin{array}{l}
\frac{x-a}{b-a}(a \leq x \leq b) \\
1(b \leq x \leq c) \\
\frac{d-x}{d-c}(c \leq x \leq d)
\end{array}\right.
$$

Where $[b, c]$ is called a mode interval of $\tilde{m}$. The lower and upper limits of $\tilde{m}$ are represented by $a$, and $b$, respectively.

\section{Problem Description}

When a ship arrives at a port, is conducted to a free berth. Then it has to unload a certain number of containers to each terminals of the associated berth. Among the containers that are arrived in each ship, there is a fraction of them have custom operation. The problem can be represented as reported in Figure1.

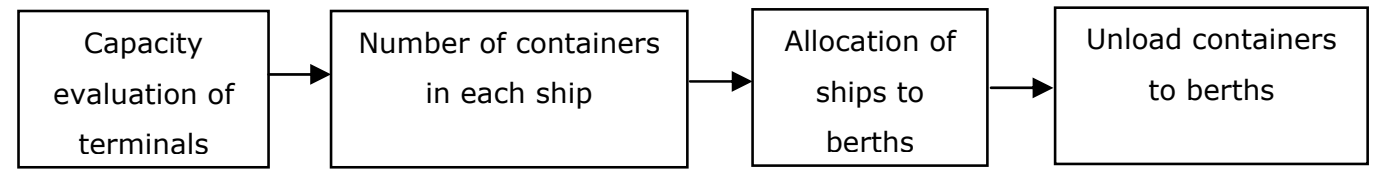

Figure 1. "Problem Representation".

\subsection{Definition of Containers Allocation in a Maritime Terminal}

Consider a container-allocation problem which is involved in solving two allocating problem simultaneously. One is allocation of ships to berths and sequentially second is related to assignment of containers to the associated terminals of that berth. The objective of is minimizing the total distance from the ship to the terminal area they are assigned. The problem can be represented by means of an acyclic directed graph, as reported in Figure 3, whose nodes represent ships, berths and terminals, while arcs model the links among nodes onto which the containers flow. 


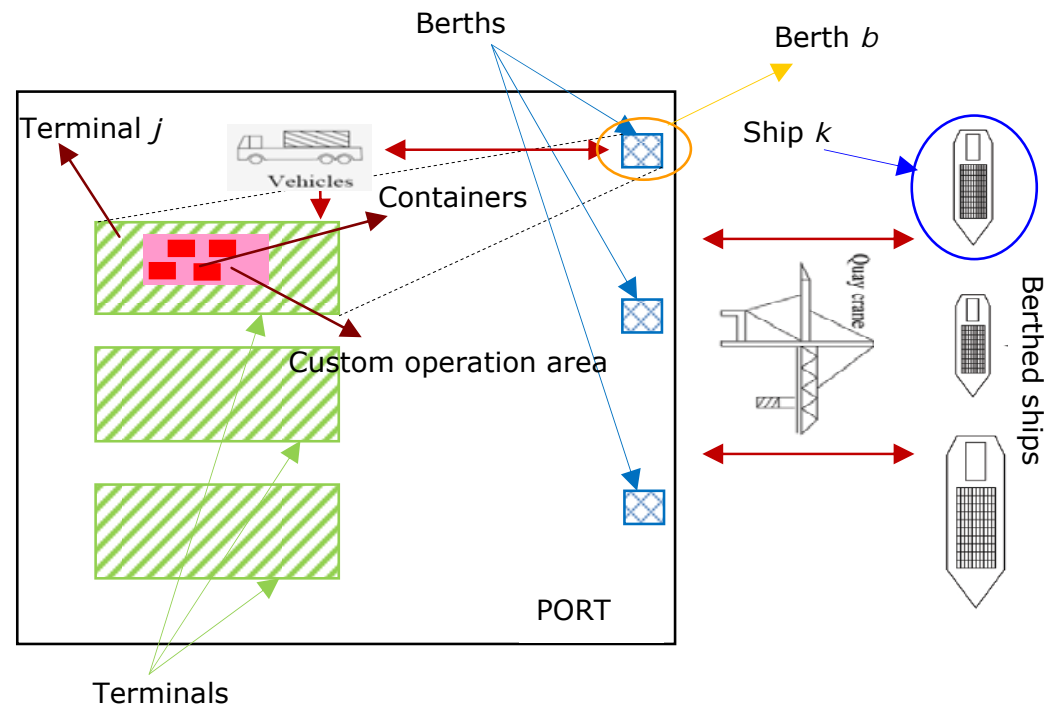

Figure 2. "Containers Allocation in Maritime Terminals".

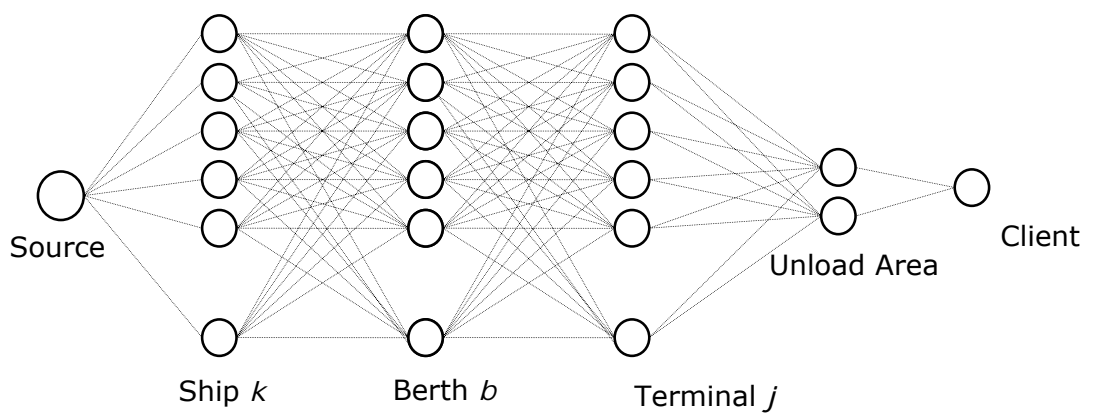

Figure 3. "Structure of Container Allocation Problem".

Assume that at time $\mathrm{t}=0$ a ship $\mathrm{k}$ is assigned a berth and has to unload a certain number of containers to terminals of that berth. The parameters of the model are as follow.

\section{s: Source node.}

$k$ : Ship index, $k=1, \ldots, n$.

b: Berth index, $b=1, \ldots, m$.

$\mathrm{j}:$ Terminal index $, \mathrm{j}=1, \ldots, \mathrm{d}$.

$\mathrm{CO}_{\mathrm{k}}$ : Number of containers associated with ship $\mathrm{k}$ that have custom operations, $\mathrm{k}=1, \ldots, \mathrm{n}$. 
$\mathrm{nco}_{\mathrm{k}}$ : Number of containers associated with ship $\mathrm{k}$ that will not be inspected, $\mathrm{k}$ $=1, \ldots, \mathrm{n}$.

P: Receiving sink.

$d_{b j}$ : Distance between berth $\mathrm{b}$ and terminal area $\mathrm{j}$ if the container does not need custom operation.

$d_{b j}^{c}$ : Sum of the distances between berth $\mathrm{b}$ and terminal area $\mathrm{j}$, and terminal area $\mathrm{j}$ and custom operation area of that terminal.

$C_{j b}$ : Available capacity of terminal $\mathrm{j}$ of berth $\mathrm{b}$.

\subsection{Formulation of the Crisp Allocation Model}

Assume that ship $\mathrm{k}$ arrives at a port and is assigned to berth $\mathrm{b}$. All containers must be unloaded in the different terminal of associated berth. The goal is to find the allocation of the containers to the terminal areas so that total distance from the berth to the terminals is minimized for all ships. The following basic assumptions are considered: (1) Each ship can be assigned to at most one berth; (2) The number of containers that can be assigned to the terminal cannot be greater than the capacity of that terminal. This capacity is a different value for each terminal at a berth; (3) Once a ship is assigned to a berth, all its containers are assigned to that berth as well.

Let us formalize the model (at a certain time $\mathrm{t}$ ), in a port with $\mathrm{m}$ berths and $\mathrm{d}$ terminal areas at each berth, in which $n$ ships arrive. It is notable that the crisp model has inherited some attributes from a model proposed in Caramia and Dell'Olmo (2008).

$$
\begin{aligned}
& \min \sum_{b=1}^{m} \sum_{j=1}^{d}\left(d c_{b j} \cdot X_{b j}^{c}+d_{b j} \cdot X_{b j}\right)+\sum_{k=1}^{n} M \cdot S_{k} \\
& \sum_{j=1}^{d} X_{b j}^{c}=\sum_{k=1}^{n} c O_{k} \cdot y_{k b}, \quad b=1, \ldots, m \\
& \sum_{j=1}^{d} X_{b j}=\sum_{k=1}^{n} n c O_{k} \cdot y_{k b}, \quad b=1, \ldots, m
\end{aligned}
$$




$$
\begin{aligned}
& \sum_{k=1}^{n} y_{k b} \leq 1, \quad b=1, \ldots, m \\
& \sum_{b=1}^{m} y_{k b}+S_{k}=1, \quad k=1, \ldots, n \\
& \left(X_{b j}+X_{b j}^{c}\right) \leq C_{b j} \quad j=1, \ldots, d, b=1, \ldots, m \\
& X_{b j} \geq 0, \forall b=1, \ldots, m, \quad j=1, \ldots, d \\
& y_{k b} \in\{0,1\}, k=1, \ldots, n, b=1, \ldots, m \\
& S_{k} \in\{0,1\}, k=1, \ldots, n
\end{aligned}
$$

The variables of models are as follow:

$X_{b j}^{c}$ : Number of assigned containers not requiring custom operation from berth $b$ to terminal area $\mathrm{j}=1, \ldots, \mathrm{d}$.

$X_{b j}$ : Number of assigned containers requiring custom operation from berth $\mathrm{b}$ to terminal area $\mathrm{j}=1, \ldots, \mathrm{d}$.

$y_{k b}$ : A $0-1$ variable equal to 1 if ship $k$ is assigned to berth $b$, and is 0 otherwise.

$S_{k}$ : A 0-1 variable, that holds 1 if ship $k$ cannot be berthed, because all the berths are busy, and has to wait, it holds 0 otherwise. Consider that this variable has a key role in selecting the ships for berthing.

The objective function has three components. The first two pieces are related to the traversed distance between berths $b$ to terminal $j$. The third part of the objective function takes into account the waiting ships. In the other word, the model guaranty that if the number of arriving ship in a period is greater than number of available berths, the most valuable combination of them is select for berthing and the others form a queue in port. Note that in the objective function $S_{k}$ is associated with a parameter $M$ that is arbitrarily high. Constraints (2), (3) assure that sum of the assigned containers from berth $b$ to terminal $j$ are equal to unloaded containers in from ship $k$ to berth $b$. Constraints (4) define that each 
berth can be assigned at most one ship at a time. Similarly, constraints (5) assign each ship to one and only one berth. Finally, constraints (6) ensure that the number of containers that are traversed from berth $b$ to terminal $j$ cannot exceed the capacity of terminal.

\subsection{Formulation of the Fuzzy Allocation Model}

In real world problem, parameters of aforementioned model are mixed with ambiguity. Consider when ships arrive at a port there is no exact evaluation of free capacity of each terminal and this often accrues due to space of berth, container combination of previous ships, total time need for container inspection and etc. The numbers of containers associated with ship $k$ that have to be inspected and the number of containers associated with ship $k$ that will not be inspected are not assumed to be predetermined exact values. It is not so unrealistic to assume that the sum of the distances between berth $b$ and terminal area $j$ has a notable amount of uncertainty because of several predefined route for quay crane in each berth. The fuzzy concepts can efficiently represent these vague nesses. Formally we consider these parameters as trapezoidal fuzzy numbers. The proposed model for designed fuzzy environment is represented as follow.

$$
\begin{aligned}
& \min \sum_{b=1}^{m} \sum_{j=1}^{d}\left(\tilde{d}_{b j}^{c} . X_{b j}^{c}+\tilde{d}_{b j} \cdot X_{b j}\right)+\sum_{k=1}^{n} M . S_{k} \\
& \sum_{j=1}^{d} X_{b j}^{c}=\sum_{k=1}^{n} \tilde{c} O_{k} \cdot y_{k b}, \quad b=1, \ldots, m \\
& \sum_{j=1}^{d} X_{b j}=\sum_{k=1}^{n} \tilde{n} c o_{k} \cdot y_{k b}, \quad b=1, \ldots, m \\
& \sum_{k=1}^{n} y_{k b} \leq 1, \quad b=1, \ldots, m \\
& \sum_{b=1}^{m} y_{k b}+S_{k}=1, \quad k=1, \ldots, n \\
& \left(X_{b j}+X_{b j}^{c}\right) \leq \tilde{C}_{b j} \quad j=1, \ldots, d, b=1, \ldots, m
\end{aligned}
$$


$X_{b j} \geq 0, \forall b=1, \ldots, m, \quad j=1, \ldots, d$

$y_{k b} \in\{0,1\}, k=1, \ldots, n, b=1, \ldots, m$

$S_{k} \in\{0,1\}, k=1, \ldots, n$

Where, $\tilde{d}_{b j}^{c}=\left(d_{b j}^{c 1}, d_{b j}^{c 2}, d_{b j}^{c 3}, d_{b j}^{c 4}\right), \quad \tilde{d}_{b j}=\left(d_{b j}^{1}, d_{b j}^{2}, d_{b j}^{3}, d_{b j}^{4}\right), \quad \tilde{c} o_{k}=\left(c o_{k}^{1}, c o_{k}^{2}, c o_{k}^{3}, c o_{k}^{4}\right)$, $n \tilde{c} o_{k}=\left(n c o_{k}^{1}, n c o_{k}^{2}, n c o_{k}^{3}, n c o_{k}^{4}\right)$, and $\tilde{C}_{b j}=\left(C_{b j}^{1}, C_{b j}^{2}, C_{b j}^{3}, C_{b j}^{4}\right)$ have same definitions which have represented in crisp model. Considering the a-cut concept, relations (10)-(18), will be transformed and the result will be an interval 0-1 programming represented as follows:

$$
\begin{aligned}
& \min \sum_{b=1}^{m} \sum_{j=1}^{d}\left(\left[d_{b j}^{L}-d_{b j}^{U}\right]_{\alpha}^{c} . X_{b j}^{c}+\left[d_{b j}^{L}-d_{b j}^{U}\right]_{\alpha} . X_{b j}\right)+\sum_{k=1}^{n} M . S_{k} \\
& \sum_{j=1}^{d} X_{b j}^{c}=\sum_{k=1}^{n}\left[c o_{k}^{L}-c o_{k}^{U}\right]_{\alpha} y_{k b}, \quad b=1, \ldots, m \\
& \sum_{j=1}^{d} X_{b j}=\sum_{k=1}^{n}\left[n c o_{k}^{L}-n c o_{k}^{U}\right]_{\alpha} . y_{k b}, \quad b=1, \ldots, m \\
& \sum_{k=1}^{n} y_{k b} \leq 1, \quad b=1, \ldots, m \\
& \sum_{b=1}^{m} y_{k b}+S_{k}=1, \quad k=1, \ldots, n \\
& \left(X_{b j}+X_{b j}^{c}\right) \leq\left[C_{b j}^{L}-C_{b j}^{U}\right]_{\alpha}, \quad j=1, \ldots, d, b=1, \ldots, m \\
& X_{b j} \geq 0, \forall b=1, \ldots, m, \quad j=1, \ldots, d \\
& y_{k b} \in\{0,1\}, k=1, \ldots, n, b=1, \ldots, m \\
& S_{k} \in\{0,1\}, k=1, \ldots, n \\
& 0 \leq \alpha \leq 1 \\
&
\end{aligned}
$$


The proposed model can be divided into two sub-model using a-cut concepts. The first one is the optimistic, and the second one is the pessimistic. In the other word these models are two extreme for aforementioned interval programming model. It is notable that lower and upper bounds of the model parameters are calculated as equations (29)-(33), respectively.

$$
\begin{aligned}
& {\left[d_{b j}^{U}\right]_{\alpha}=d_{b j}^{4}-\alpha\left(d_{b j}^{4}-d_{b j}^{3}\right) ; \quad\left[d_{b j}^{L}\right]_{\alpha}=d_{b j}^{1}+\alpha\left(d_{b j}^{2}-d_{b j}^{1}\right) ; \quad 0 \leq \alpha \leq 1} \\
& {\left[d_{b j}^{U}\right]_{\alpha}^{c}=d_{b j}^{c 4}-\alpha\left(d_{b j}^{c 4}-d_{b j}^{c 3}\right) ; \quad\left[d_{b j}^{L}\right]_{\alpha}^{c}=d_{b j}^{c 1}+\alpha\left(d_{b j}^{c 2}-d_{b j}^{c 1}\right) ; \quad 0 \leq \alpha \leq 1} \\
& {\left[c o_{k}^{U}\right]_{\alpha}=c o_{k}^{4}-\alpha\left(c o_{k}^{4}-c o_{k}^{3}\right) ; \quad\left[c o_{k}^{L}\right]_{\alpha}=c o_{k}^{1}+\alpha\left(c o_{k}^{2}-c o_{k}^{1}\right) ; \quad 0 \leq \alpha \leq 1} \\
& {\left[n c O_{k}^{U}\right]_{\alpha}=n c O_{k}^{4}-\alpha\left(n c O_{k}^{4}-n c O_{k}^{3}\right) ; \quad\left[n c O_{k}^{L}\right]_{\alpha}=n c o_{k}^{1}+\alpha\left(n c o_{k}^{2}-n c O_{k}^{1}\right) ; \quad 0 \leq \alpha \leq 1} \\
& {\left[C_{b j}^{U}\right]_{\alpha}=C_{b j}^{4}-\alpha\left(C_{b j}^{4}-C_{b j}^{3}\right) ; \quad\left[C_{b j}^{L}\right]_{\alpha}=C_{b j}^{1}+\alpha\left(C_{b j}^{2}-C_{b j}^{1}\right) ; \quad 0 \leq \alpha \leq 1}
\end{aligned}
$$

In optimistic model the distances and number of containers in each arrived ship, are assumed equal to lower bound of associated interval programming while the available capacity of a terminal in each berth are set equal to upper bound of interval program. These values are set inversely for pessimistic programming. The proposed models should be solved for predefined a-cut levels in order to complete a full analysis. In the next section the full analysis will be represented for an illustrative instance.

\section{Experimental Results}

In this section, the proposed model is tested. A full analysis is performed with both optimistic and pessimistic models using two different a-cut levels for an instance.

\subsection{Test Problem}

We consider a BAP instance problem as a triple like $(5,5,5)$ which first argument is dedicated for number of ships, second and third arguments represent the number of berths in port and number of terminals in each berths, respectively. More information is presented in the following table. It is notable that all data are TrFNs.

\begin{tabular}{|c|c|c|}
\hline & CO & NCO \\
\hline SHIP1 & $(33,67,71,113)$ & $(22,72,82,112)$ \\
\hline
\end{tabular}




\begin{tabular}{|c|c|c|}
\hline SHIP2 & $(40,45,93,120)$ & $(19,48,72,88)$ \\
\hline SHIP3 & $(4,15,31,33)$ & $(12,18,26,102)$ \\
\hline SHIP4 & $(43,44,46,47)$ & $(8,16,32,59)$ \\
\hline SHIP5 & $(50,132,135,157)$ & $(39,45,51,53)$ \\
\hline
\end{tabular}

Table 1. "Number of Containers in each ship".

\begin{tabular}{|c|c|c|c|c|c|}
\hline & TER1 & TER2 & TER3 & TER4 & TER5 \\
\hline BERTH1 & $(18,23,28,37)$ & $(53,58,60,67)$ & $(20,27,36,41)$ & $(64,70,73,77)$ & $(33,36,41,50)$ \\
\hline BERTH2 & $(5,11,15,17)$ & $(26,28,29,36)$ & $(5,7,8,8)$ & $(35,42,42,48)$ & $(6,10,11,16)$ \\
\hline BERTH3 & $(74,83,89,89)$ & $(33,38,43,49)$ & $(59,64,70,77)$ & $(57,64,70,70)$ & $(29,37,39,39)$ \\
\hline BERTH4 & $(17,20,23,23)$ & $(52,54,54,56)$ & $(92,96,101,105)$ & $(39,40,49,52)$ & $(75,80,88,89)$ \\
\hline BERTH5 & $(4,8,10,18)$ & $(71,71,79,83)$ & $(65,71,79,87)$ & $(23,32,41,50)$ & $(26,26,31,35)$ \\
\hline
\end{tabular}

Table 2. "Available Capacity of each Terminal in a Berth".

\begin{tabular}{|c|c|c|c|c|c|}
\hline & TER1 & TER2 & TER3 & TER4 & TER5 \\
\hline BERTH1 & $(29,104,132,189)$ & $(14,31,61,106)$ & $(8,28,41,109)$ & $(15,38,98,118)$ & $(27,32,48,90)$ \\
\hline BERTH2 & $(36,106,108,109)$ & $(26,27,35,45)$ & $(1,40,96,164)$ & $(30,48,74,86)$ & $(30,41,48,50)$ \\
\hline BERTH3 & $(46,60,145,185)$ & $(36,47,55,73)$ & $(14,14,58,88)$ & $(40,53,69,70)$ & $(26,40,46,52)$ \\
\hline BERTH4 & $(39,44,102,154)$ & $(21,100,113,117)$ & $(6,6,56,106)$ & $(37,38,122,180)$ & $(11,27,51,104)$ \\
\hline BERTH5 & $(14,25,78,119)$ & $(37,65,110,111)$ & $(30,62,153,164)$ & $(43,46,69,85)$ & $(25,83,85,92)$ \\
\hline
\end{tabular}

Table 3. "Distance between Berth b and Terminal area j for I containers".

\begin{tabular}{|c|c|c|c|c|c|}
\hline & TER1 & TER2 & TER3 & TER4 & TER5 \\
\hline BERTH1 & $(3,32,43,68)$ & $(22,23,43,66)$ & $(4,5,20,45)$ & $(3,20,21,36)$ & $(19,43,56,142)$ \\
\hline BERTH2 & $(8,45,55,55)$ & $(29,29,70,83)$ & $(14,50,124,138)$ & $(42,62,84,90)$ & $(20,42,74,116)$ \\
\hline BERTH3 & $(26,43,53,113)$ & $(15,34,36,93)$ & $(14,64,116,117)$ & $(18,33,36,76)$ & $(5,72,120,122)$ \\
\hline BERTH4 & $(22,28,46,55)$ & $(31,39,75,105)$ & $(38,79,114,162)$ & $(39,51,58,130)$ & $(48,56,69,124)$ \\
\hline BERTH5 & $(37,86,99,142)$ & $(39,47,48,89)$ & $(3,32,48,54)$ & $(49,69,79,82)$ & $(38,38,68,103)$ \\
\hline
\end{tabular}

Table 4. "Distance between Berth b and Terminal area j for NI containers".

\subsection{Results}

The described instance was solved optimally by LINGO 8.0 solver through a Branch $\&$ Bound algorithm. The optimistic and the pessimistic model were solved for different a-cut levels. The obtained results are summarized in following tables.

\begin{tabular}{|c|c|c|c|c|}
\hline \multicolumn{3}{|c|}{ Optimistic Programming } & \multicolumn{2}{c|}{} \\
\hline Run & a-cut level & O.F.V. & State & Iteration \\
\hline 1 & 0 & 2453.000 & Global Optimum & 48 \\
\hline 2 & 1 & 11230.00 & Global Optimum & 63 \\
\hline \multicolumn{2}{|c|}{ Pessimistic Programming } & \multicolumn{2}{c|}{} \\
\hline Run & a-cut level & O.F.V. & State & Iteration \\
\hline 1 & 0 & $0.10 \mathrm{E}+14$ & Global Optimum & 529 \\
\hline 2 & 1 & 30400.00 & Global Optimum & 64 \\
\hline
\end{tabular}

Table 5. "Objective Function Value".

\begin{tabular}{|c|c|c|c|c|c|c|c|c|c|c|c|}
\hline \multicolumn{12}{|c|}{ Number Of Assigned Custom Operation Required Container to each Terminal } \\
\hline \multicolumn{6}{|c|}{ a-cut $=0$} & \multicolumn{6}{|c|}{ a-cut $=1$} \\
\hline$X_{b j}^{c}$ & TER1 & TER2 & TER3 & TER4 & TER5 & $X_{b j}^{c}$ & TER1 & TER2 & TER3 & TER4 & TER5 \\
\hline BERTH1 & 0 & 9 & 41 & 0 & 0 & BERTH1 & 0 & 45 & 0 & 0 & 0 \\
\hline BERTH2 & 0 & 0 & 4 & 0 & 0 & BERTH2 & 0 & 29 & 8 & 0 & 7 \\
\hline BERTH3 & 0 & 0 & 40 & 0 & 0 & BERTH3 & 0 & 0 & 67 & 0 & 0 \\
\hline BERTH4 & 0 & 0 & 43 & 0 & 0 & BERTH4 & 0 & 0 & 101 & 0 & 31 \\
\hline
\end{tabular}




\begin{tabular}{|c|c|c|c|c|c|c|c|c|c|c|c|}
\hline BERTH5 & 18 & 0 & 0 & 0 & 15 & BERTH5 & 10 & 0 & 0 & 5 & 0 \\
\hline \multicolumn{12}{|c|}{ Number Of Assigned No Custom Operation Required Container to each Terminal } \\
\hline \multicolumn{6}{|c|}{ a-cut $=0$} & \multicolumn{6}{|c|}{ a-cut $=1$} \\
\hline$X_{b j}$ & TER1 & TER2 & TER3 & TER4 & TER5 & $X_{b j}$ & TER1 & TER2 & TER3 & TER4 & TER5 \\
\hline BERTH1 & 37 & 0 & 0 & 2 & 0 & BERTH1 & 0 & 0 & 36 & 12 & 0 \\
\hline BERTH2 & 12 & 0 & 0 & 0 & 0 & BERTH2 & 12 & 0 & 0 & 0 & 4 \\
\hline BERTH3 & 0 & 0 & 0 & 0 & 19 & BERTH3 & 0 & 2 & 0 & 70 & 0 \\
\hline BERTH4 & 8 & 0 & 0 & 0 & 0 & BERTH4 & 23 & 22 & 0 & 0 & 0 \\
\hline BERTH5 & 0 & 0 & 22 & 0 & 0 & BERTH5 & 0 & 0 & 18 & 0 & 0 \\
\hline \multicolumn{12}{|c|}{ Ship Allocation to Berth } \\
\hline \multicolumn{6}{|c|}{ a-cut $=0$} & \multicolumn{6}{|c|}{ a-cut $=1$} \\
\hline $\mathrm{Y}_{\mathrm{kb}}$ & BERTH1 & BERTH2 & BERTH3 & BERTH4 & BERTH5 & $\mathrm{Y}_{\mathrm{kb}}$ & BERTH1 & BERTH2 & BERTH3 & BERTH4 & BERTH5 \\
\hline SHIP1 & 0 & 0 & 0 & 0 & 1 & SHIP1 & 0 & 0 & 1 & 0 & 0 \\
\hline SHIP2 & 0 & 0 & 1 & 0 & 0 & SHIP2 & 1 & 0 & 0 & 0 & 0 \\
\hline SHIP3 & 0 & 1 & 0 & 0 & 0 & SHIP3 & 0 & 0 & 0 & 0 & 1 \\
\hline SHIP4 & 0 & 0 & 0 & 1 & 0 & SHIP4 & 0 & 1 & 0 & 0 & 0 \\
\hline SHIP5 & 1 & 0 & 0 & 0 & 0 & SHIP5 & 0 & 0 & 0 & 1 & 0 \\
\hline
\end{tabular}

Table 6. "Solution Structure for Optimistic Programming".

\begin{tabular}{|c|c|c|c|c|c|c|c|c|c|c|c|}
\hline \multicolumn{12}{|c|}{ Number Of Assigned Custom Operation Required Container to each Terminal } \\
\hline \multicolumn{6}{|c|}{ a-cut $=0$} & \multicolumn{6}{|c|}{ a-cut $=1$} \\
\hline$X_{b j}^{c}$ & TER1 & TER2 & TER3 & TER4 & TER5 & $X_{b j}^{c}$ & TER1 & TER2 & TER3 & TER4 & TER5 \\
\hline BERTH1 & 0 & 0 & 0 & 0 & 33 & BERTH1 & 0 & 20 & 15 & 0 & 36 \\
\hline BERTH2 & 0 & 0 & 0 & 0 & 0 & BERTH2 & 0 & 28 & 0 & 0 & 3 \\
\hline BERTH3 & 0 & 32 & 59 & 0 & 29 & BERTH3 & 0 & 30 & 26 & 0 & 37 \\
\hline BERTH4 & 0 & 0 & 82 & 0 & 75 & BERTH4 & 0 & 0 & 55 & 0 & 80 \\
\hline BERTH5 & 0 & 0 & 0 & 23 & 24 & BERTH5 & 8 & 0 & 0 & 32 & 6 \\
\hline \multicolumn{12}{|c|}{ Number Of Assigned No Custom Operation Required Container to each Terminal } \\
\hline \multicolumn{6}{|c|}{$\mathrm{a}$-cut $=0$} & \multicolumn{6}{|c|}{$\mathrm{a}$-cut $=1$} \\
\hline$X_{b j}$ & TER1 & TER2 & TER3 & TER4 & TER5 & $X_{b j}$ & TER1 & TER2 & TER3 & TER4 & TER5 \\
\hline BERTH1 & 0 & 18 & 20 & 64 & 0 & BERTH1 & 0 & 0 & 12 & 70 & 0 \\
\hline BERTH2 & 0 & 0 & 0 & 0 & 0 & BERTH2 & 11 & 0 & 0 & 8 & 7 \\
\hline BERTH3 & 30 & 1 & 0 & 57 & 0 & BERTH3 & 0 & 8 & 0 & 64 & 0 \\
\hline BERTH4 & 17 & 36 & 0 & 0 & 0 & BERTH4 & 20 & 0 & 0 & 31 & 0 \\
\hline BERTH5 & 0 & 0 & 59 & 0 & 0 & BERTH5 & 0 & 0 & 32 & 0 & 0 \\
\hline \multicolumn{12}{|c|}{ Ship Allocation to Berth } \\
\hline \multicolumn{6}{|c|}{$a-$ cut $=0$} & \multicolumn{6}{|c|}{ a-cut $=1$} \\
\hline $\mathrm{Y}_{\mathrm{kb}}$ & BERTH1 & BERTH2 & BERTH3 & BERTH4 & BERTH5 & $\mathrm{Y}_{\mathrm{kb}}$ & BERTH1 & BERTH2 & BERTH3 & BERTH4 & BERTH5 \\
\hline SHIP1 & 0 & 0 & 0 & 0 & 0 & SHIP1 & 1 & 0 & 0 & 0 & 0 \\
\hline SHIP2 & 0 & 0 & 1 & 0 & 0 & SHIP2 & 0 & 0 & 1 & 0 & 0 \\
\hline SHIP3 & 1 & 0 & 0 & 0 & 0 & SHIP3 & 0 & 1 & 0 & 0 & 0 \\
\hline SHIP4 & 0 & 0 & 0 & 0 & 1 & SHIP4 & 0 & 0 & 0 & 0 & 1 \\
\hline SHIP5 & 0 & 0 & 0 & 1 & 0 & SHIP5 & 0 & 0 & 0 & 1 & 0 \\
\hline
\end{tabular}

Table 7. "Solution Structure for Pessimistic Programming"

The results show the robustness of proposed models in an ambiguous environment. Formally, the proposed model act optimally in two steps. In first step, it allocates the arrived ships to berths and sequentially in second step determines number of containers which should be assigned to each terminal of a berth. The model performs all these allocations subject to detachment of containers need for custom operations and those don't need. 


\section{Summary and Conclusions}

In this paper we have developed a 0-1 programming models for Containers Allocation Problem in Maritime Terminals in crisp and fuzzy environment. In the proposed fuzzy model, the distances between berth and terminals area, number of containers in an arrived ship and estimation of available area in each terminal at a port was assumed in an ambiguous condition. The developed model consisted of two major steps. In first step, it allocates the arrived ships to berths and sequentially in second step determines number of containers which should be assigned to each terminal of a berth. The parameters of the model were assumed to be fuzzy due to adaptation with real world ambiguous conditions. We used TrFNs to represent the vagueness. Using a-cut level concepts, we developed 2 different models, one for optimistic and the other for pessimistic condition. The proposed models were coded in LINGO 8.0 solver and a test problem was solved in different a-cut levels. The obtained results show that the proposed procedure is robust. The optimum assignment of ship to berths and containers to terminal subject to different constraints and minimizing total traversed distance by quay cranes and heavy transshipment vehicles in a full fuzzy environment, are major output of proposed model.

\section{References}

Canonaco, P., Legato, P., Mazza, R.M., \& Musmanno, R. (2008). A queuing network model for the management of berth crane operations. Computers \& Operations Research, 35, 2432-2446.

Caramia, M., \& Dell'Olmo, P. (2008). Multi-objective Management in Freight Logistics: Increasing Capacity, Service Level and Safety with Optimization Algorithms. London: Springer-Verlag.

Cordeau, J.-F., Gaudioso, M.; Laporte, G., Moccia, L. (2007). The service allocation problem at the Gioia Tauro Maritime Terminal. European Journal of Operational Research, 176, 1167-1184.

Hansen, P., Oguz, C., \& Mladenovic, N. (2008). Variable neighborhood search for minimum cost berth allocation. European Journal of Operational Research, 191, 636-649. 
Imai, A., Chia Chen, H., Nishimura, E., \& Papadimitriou, S. (2008). The simultaneous berth and quay crane allocation problema. Transportation Research, Part E (44), 900-920.

Imai, A., Nishimura, E., Hattori, M., \& Papadimitriou, S. (2007). Berth allocation at indented berths for mega-containerships. European Journal of Operational Research, 179, 579-593.

Imai, A., Nishimura, E., Papadimitriou, S. (2008). Berthing ships at a multi-user container terminal with a limited quay capacity. Transportation Research, Part E (44), 136-151.

Li, J.-A., Leung, S.C.H., Wu, Y., \& Liu, K. (2007). Allocation of empty containers between multi-ports. European J ournal of Operational Research, 182, 400-412.

Liang, C., Huang, Y., Yang, Y., \& Crane, Q. (in press). Dynamic Scheduling Problem by Hybrid Evolutionary Algorithm for Berth Allocation Planning. Computers \& Industrial Engineering.

Wang, F., \& Lim, A. (2007). A stochastic beam search for the berth allocation problema. Decision Support Systems, 42 2186-2196.

(C) Journal of Industrial Engineering and Management, 2009 (www.jiem.org)

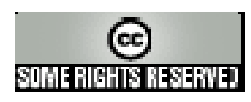

Article's contents are provided on a Attribution-Non Commercial 3.0 Creative commons license. Readers are allowed to copy, distribute and communicate article's contents, provided the author's and Journal of Industrial Engineering and Management's names are included. It must not be used for commercial purposes. To see the complete license contents, please visit http://creativecommons.org/licenses/by-nc/3.0/. 